\title{
HYPERTENSION DUE TO SYPHILITIC OCCLUSION OF THE MAIN RENAL ARTERIES
}

\author{
BY \\ R. KEMBALL PRICE AND R. SKELTON \\ From the Cardiac Department of the Royal Sussex County Hospital
}

Received November 20, 1947

This is the record of a case of hypertension starting in childhood and leading to death from heart failure at the age of 24 . There is strong presumptive evidence that the hypertension was preceded by occlusion of the main renal arteries.

\section{CASE REPORT}

Irene H., single, aged 24 years, was admitted to hospital on January 1, 1947, with severe heart failure.

Family History.-Her father suffered from asthma and was killed at the age of 26 . One brother was killed in the Second World War. The mother and three sisters are alive and well.

Past History.-When aged 4, she had an operation for intussusception; a gland was removed and a diagnosis of mesenteric tuberculosis was made. When 8 , she had diphtheria with no complications.

Present History.-At the age of 13, when running in a race, she became unduly breathless and on examination was said to have an " enlarged heart." Soon after this she was diagnosed as having pulmonary tuberculosis on some shadowing in the lung fields, and was treated in a sanatorium for six months. An X-ray taken at this time showed cardiac enlargement and pulmonary œdema (Fig. 1). She remained afebrile throughout and the sputum was never positive for tubercle. An X-ray four months later showed lungs " much clearer"; the heart was unchanged. She remained under observation by the Tuberculosis Officer for the next four years. On several occasions heart sounds were noted as loud and ringing but there was no record of the blood pressure. Her doctor states that for the last six years he has treated her for recurrent attacks of left ventricular failure and recently for congestive failure as well. Ten days before admission to hospital she developed a "cold," followed by increasing dyspnœa.

Examination.-Pale and orthopnœic, venous pul- sation in the neck and visible pulsation in the brachial arteries. No clubbing of the fingers. Pulse 120, regular, very small volume. Apex beat $16 \mathrm{~cm}$. from the mid-line, heaving. First sound at the apex loud; aortic second sound very loud and an aortic diastolic murmur audible at the second right costal cartilage. Triple rhythm present due to the addition of a fourth heart sound. Blood pressure $210 / 100 \mathrm{~mm}$. Harsh breath sounds with diffuse rhonchi over the right lower lobe, and coarse crepitations at both bases. Liver enlarged $5 \mathrm{~cm}$. below costal margin; moderate œedema of the ankles and over the sacrum. Retinal arteries narrow and bright; no hæmorrhages or exudate. The urine contained a trace of albumin and the deposit showed occasional epithelial cells only.

A radiograph showed considerable enlargement of the left ventricle, diffuse dilatation of the aorta with some calcification in the aortic knuckle, and patchy pulmonary œdema (Fig. 2).

An electrocardiogram showed left ventricular preponderance with $R-T$ depression and $T$ wave inversion in leads I and CR7, a diphasic $T$ wave in lead II and R-T elevation in lead III, and a biphasic $P$ wave in lead III.

Renal function: blood urea, $70 \mathrm{mg}$. per $100 \mathrm{ml}$.; urea clearance (1) $37 \mathrm{ml} .3 \cdot 3$ per cent urea; standard clearance 68 per cent; (2) $12 \mathrm{ml} .3 .4$ per cent urea; standard clearance 40 per cent.

Blood count: R.B.C., 3.99 million per c.mm. Hæmoglobin 82 per cent, colour index 1.0, W.B.C., 12,000 per c.mm. Wassermann reaction $( \pm)$.

Progress.-Under treatment by complete rest, oxygen, digitalis, and mercurial diuretics she showed some temporary improvement, and the œdema of the legs disappeared. Twelve days after admission she died suddenly.

\section{NeCROPSY REPORT}

The body of a thin, but not emaciated, young woman of medium height showing engorgement of 


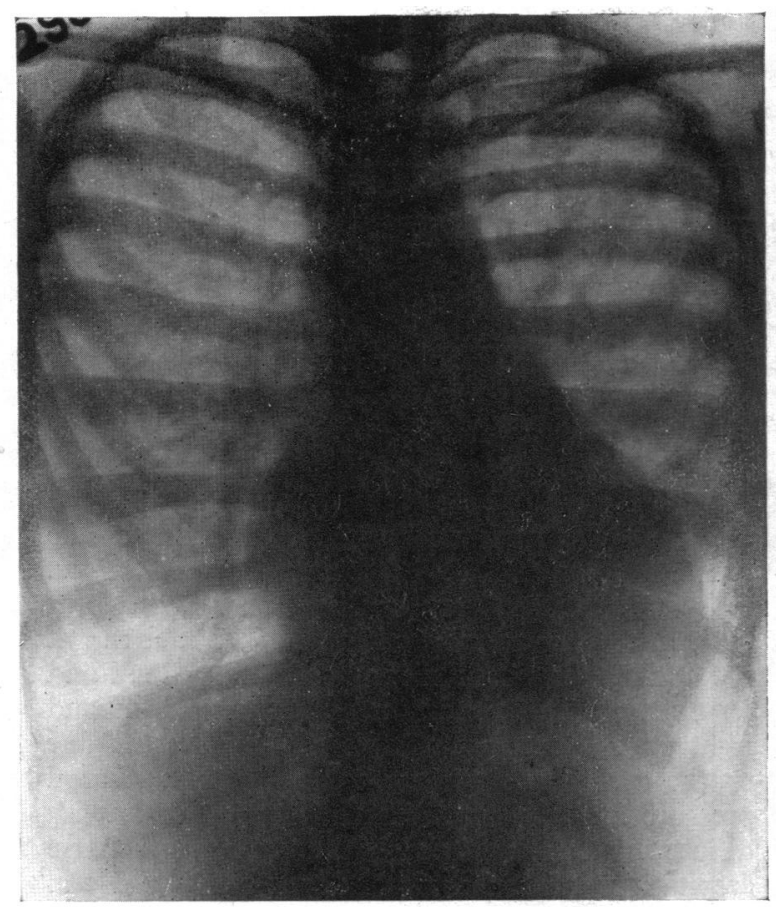

Fig. 1.-Radiograph at age of 13 showing left ventricular enlargement and pulmonary œdema involving upper and mid zones (August 23, 1936).

the veins of the neck and cyanosis of lips and ears. Slight œdema at the ankles, no ascites; no jaundice or clubbing of fingers. Nothing in the facies to suggest congenital syphilis.

The abdominal cavity contains about $100 \mathrm{ml}$. of clear straw-coloured fluid. Both pleural cavities contain about $200 \mathrm{ml}$. of clear fluid; no adhesions. The pericardial cavity contains about $20 \mathrm{ml}$. of clear yellow fluid, and there are fine adhesions between the anterior aspect of the left ventricle and the parietal pericardium, of fairly recent origin.

The mouth shows no noteworthy change, tonsils not enlarged, no abnormalities of the teeth. The trachea and bronchi contain frothy œdema fluid; œsophagus appears normal.

The heart (Fig. 3) is much enlarged and weighs 890 grams. There is great left ventricular hypertrophy, and moderate hypertrophy with considerable dilatation of the other chambers. Thickness of right auricle, $2 \mathrm{~mm}$.; right ventricle, $8 \mathrm{~mm}$; left auricle, $4 \mathrm{~mm}$.; left ventricle, $24 \mathrm{~mm}$; circumference of orifice of pulmonary artery, $7.5 \mathrm{~cm}$.; of tricuspid valve, $12 \mathrm{~cm}$.; of mitral valve, $8.5 \mathrm{~cm}$.; of aorta at origin, $12.5 \mathrm{~cm}$. The right heart showed the greater dilatation. Both auriculo-ventricular

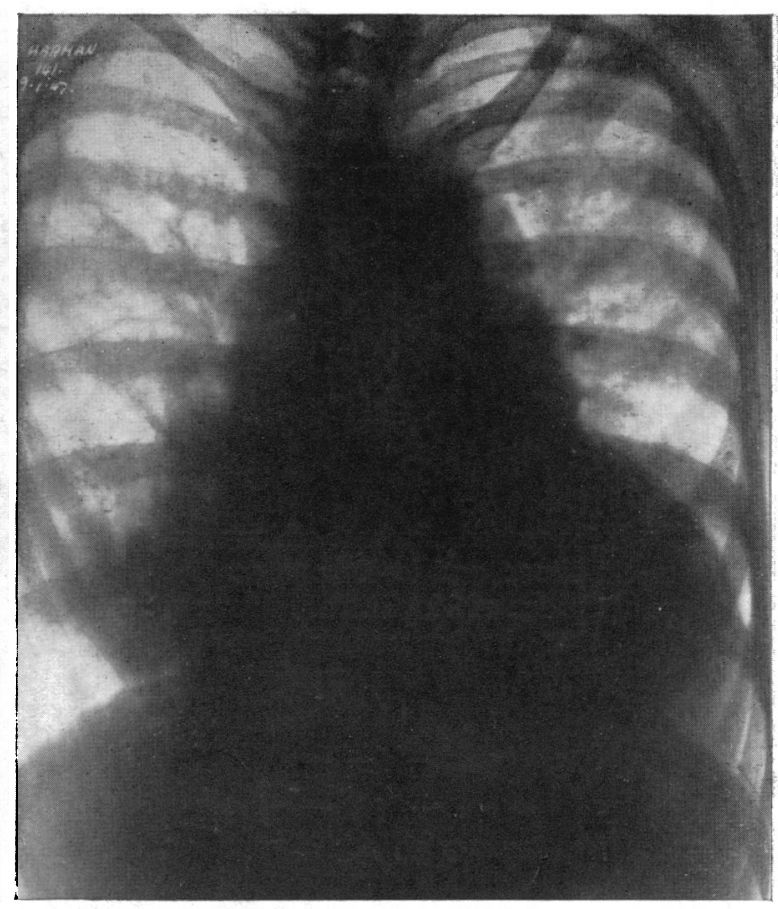

Fig. 2.-Radiograph at age of 24 showing left ventricular enlargement, aortic dilatation, and patchy pulmonary œdema (January 9, 1947).

valve rings are dilated; valve cusps normal. The pulmonary valve cusps appear normal. The pulmonary artery shows a few small atheromatous patches. The left auricle is dilated. The left ventricle is greatly hypertrophied, there are a number of old fibrous scars in the myocardium, and an area of fibrous infarction lying anteriorly towards the apex. The aortic valve cusps show slight rolling of the free margins of the cusps and some fibrous thickening, without separation of the commissures. The coronary arteries are considerably dilated, tortuous, thickened, and show intimal calcification. The first part of aorta is generally dilated beyond the sinuses of Valsalva, where the diameter is $12.5 \mathrm{~cm}$. Throughout its length, the aorta shows patchy intimal thickening, with calcification, and linear scarring associated with atherosclerosis, the whole intima being covered by plaques, some calcified and many ulcerated with small thrombi upon them. In addition to these generalized lesions of the intima, there are two curious lesions that appear to have arisen as dissecting aneurysms. The first of these is situated in the thoracic portion, $4.5 \mathrm{~cm}$. distal to the origin of the innominate artery, and consists of a crescentic fold in the wall, 
concavity downwards, lined by intima. There appears to have been a cleavage in the wall of the aorta occurring after the manner of a dissecting aneurysm, which has become arrested and subsequently lined by intima.

The second lesion, situated $4 \mathrm{~cm}$. below the diaphragm in the abdominal aorta, is an aneurysmal swelling $4.5 \mathrm{~cm}$. in length and $3 \mathrm{~cm}$. in diameter, presenting anteriorly, and communicating with the aortic lumen by two orifices, separated from one another by a bridge of aortic tissue. The appearance is that of a dissecting aneurysm which has re-entered the aorta just below its origin. Just above the bifurcation, the aorta shows a gross fusiform aneurysmal dilatation. The common iliac vessels are both much dilated to form fusiform aneurysms the walls of which are lined by adherent laminated blood clot.

At the orifices of the renal arteries, the aorta is grossly distorted by scar tissue, so that the renal vessels appear to be lying in small funnel-shaped depressions (Fig. 4). Both renal vessels are fibrous throughout the greater part of their length, and their lumina are reduced to a pinpoint or small slit lying to the side of the vessel, so that there must have been extreme reduction of renal blood flow during life. The carotids, innominate, cœliac axis and its main branches, and superior mesenteric artery all show great intimal thickening and scarring with general dilatation of the lumina.

The lungs show considerable œdema and chronic pulmonary congestion. There is no evidence of tuberculosis. The liver is slightly enlarged, dark red on section and shows acute venous congestion. The gall bladder and bile ducts are normal. The pancreas is healthy and the adrenals are normal.

The left kidney is smaller and narrower than the right; weight $150 \mathrm{~g}$., length $11 \mathrm{~cm}$., width $5.5 \mathrm{~cm}$., thickness $3.5 \mathrm{~cm}$.; cortex $4 \mathrm{~mm}$.; medulla $16 \mathrm{~mm}$. Right kidney, weight 180 g., length $10.5 \mathrm{~cm}$., width $7 \mathrm{~cm}$., thickness $4 \mathrm{~cm}$.; cortex $6 \mathrm{~mm}$., medulla $16 \mathrm{~mm}$. In both kidneys the capsules strip readily, leaving a perfectly smooth surface. There is no undue prominence of the intra-renal vessels. The main renal arteries show occlusive lesions as already described.

The renal pelves, ureters, and bladder appear normal. The uterus and adnexæ are normal. The stomach and intestines show no macroscopic lesions. Cranial cavity not examined.

\section{Histology}

Aorta.-The adventitia shows a diffuse plasma cell and lymphocyte infiltration, with cellular cuffing of the vasa vasorum. The media shows

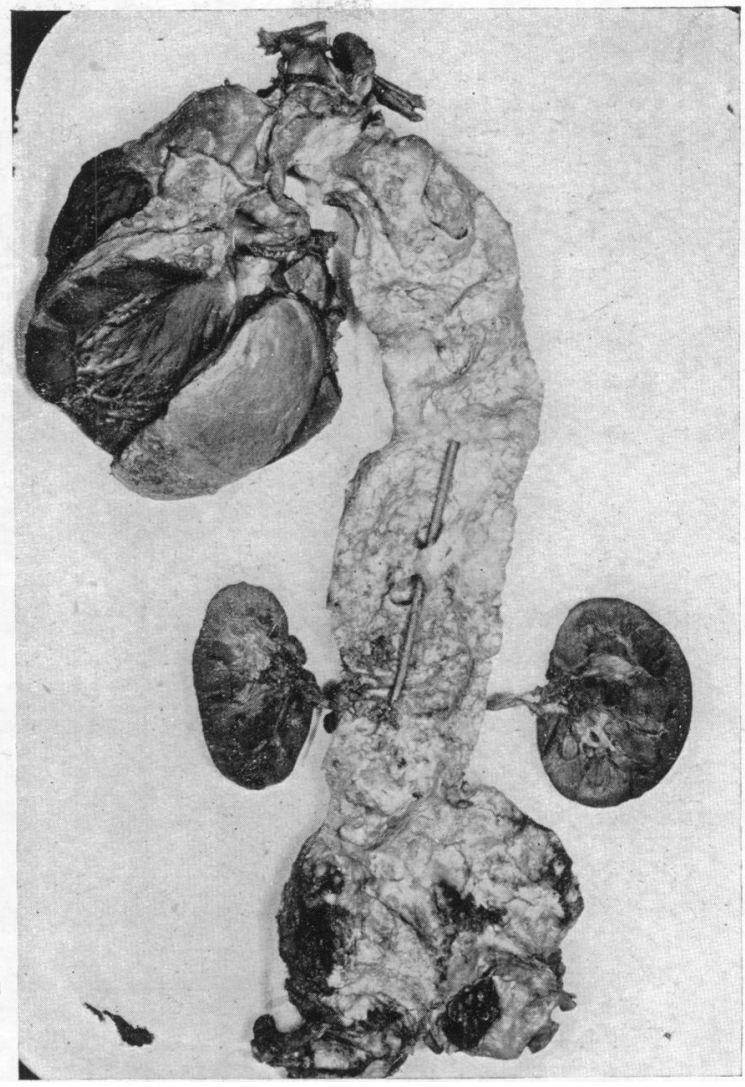

FIG. 3.-Necropsy specimen showing left ventricular hypertrophy, severe syphilitic aortitis, and iliac aneurysms.

much fibrosis and interruption of the elastic fibres. The intima is thickened, and calcified in places. A similar appearance of syphilitic arteritis is seen in the carotid artery on section.

Renal Arteries. The right renal artery shows great intimal thickening at its origin without active changes in the media of adventitia and there is no atheroma at this point; the lumen is stenosed for a distance of $1 \mathrm{~cm}$. and then widens.

The left renal artery at its origin shows great thickening of the intima which reduces the lumen to minute proportions. The intimal tissue is loose and cellular and infiltrated with lymphocytes and a few plasma cells. There is no active arteritis of the media or adventitia, and no evident atheroma in either of the sections.

Kidneys.-Right: glomeruli appear normal, no arteriolar hyalinization and no post-hypertensive changes in the interlobular vessels. Tubules show post-mortem changes only. Left: similar to the 


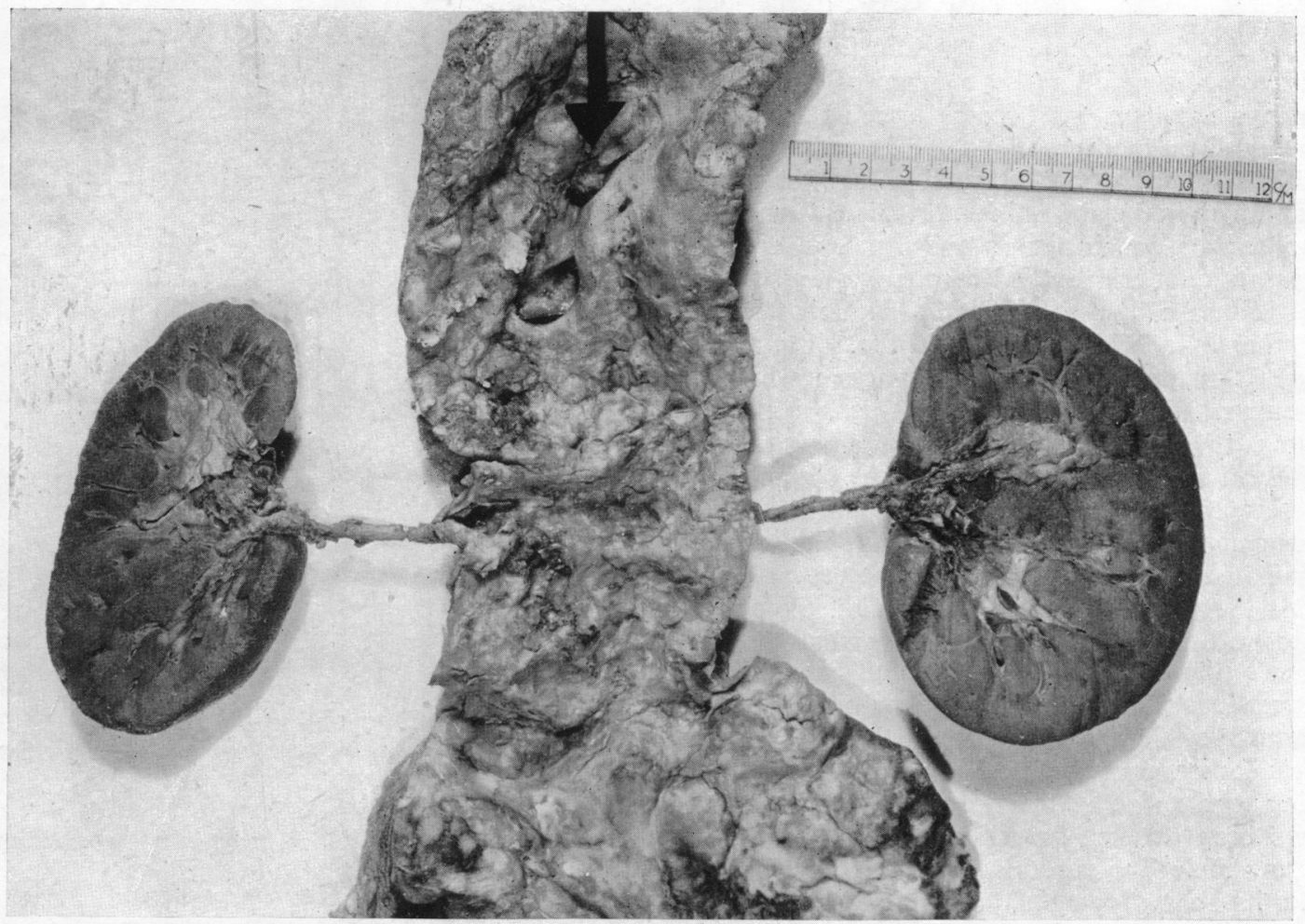

FIG. 4.-Necropsy specimen showing severe aortitis with healed dissection marked by arrow, involvement of orifices of renal arteries, and iliac aneurysms containing laminated thrombi.

right, but there are a very few scattered fibrosed glomeruli surrounded by small groups of plasma cells and lymphocytes; no arteriolar lesions.

Pancreas is autolysed and shows conspicuous post-hypertensive arteriolar lesions. Lung shows chronic venous congestion, with " heart failure cells" in the alveoli; no vascular lesions. Liver shows acute venous congestion; no arteriolar lesions. Adrenals, normal; no arteriolar lesions.

\section{Discussion}

Several cases showing occlusive lesions of the renal arteries associated with essential hypertension have been reported, and hypertensive arteriolar changes occurred in all organs except the kidneys in which the arterioles are protected from the blast of high blood pressure by occlusion of the main renal arteries. The occlusion was usually atheromatous, but occasionally due to other causes. Blatt and Page (1939) recorded obstruction of the renal arteries by sarcomatous tissue, in a man aged 38 with hypertension. Leiter (1938) described syphilitic occlusion of the renal artery in a woman aged 46; and thrombosis of the renal arteries, usually secondary to atheroma, has also been described (Wolffe and Donnelly, 1942). In our case, both renal arteries were almost occluded by intimal proliferation from extensive syphilitic arteritis, and though atheroma was also present, it was probably a secondary lesion.

It is tempting to explain hypertension associated with atheroma of the renal arteries in terms of a reduced blood supply to the kidneys, but such a conclusion must be accepted with caution. Atheroma of the renal arteries is by no means uncommon, occurring in about 10 per cent of necropsies in subjects without hypertension, and it is possible that hypertension merely aggravates pre-existing atherosclerotic lesions. When renal arterial occlusion is syphilitic, there is more reason to regard it as the cause of the hypertension, and in our case this supposition is supported by the fact that the renal arterioles showed no hypertensive changes whereas the pancreatic arterioles showed them in high degree. Hypertension evidently began at least 11 years before death, for cardiac enlargement 
and pulmonary congestion were shown in radiographs taken at that time. The aneurysmal dilatation of the common iliac vessels and the two aneurysmal lesions of the aorta may have been due to hypertension superimposed on arteries already weakened by syphilitic inflammation.

\section{SUMmaRY}

A case of syphilitic aortitis with aneurysmal lesions of the aorta and common iliac vessels, and occlusion of the renal arteries by syphilitic arteritis is described. Hypertension was known to have been present for many years, and it is suggested that it was secondary to renal arterial occlusion.

We wish to thank Sir John Parkinson for reading this report and for his helpful criticism.

\section{REFERENCES}

Blatt, E., and Page, I. H. (1939). Ann. intern. Med., 12, Leiter, L. (1938). J. Amer. med. Ass., 111, 507. 1690. 